\section{References}

Commission of the European Communities (2005) Improving the Mental Health of the Population (green paper). COM 484 final. Brussels: CEC.

Commission for the Realisation of Reform of Psychiatric Care (2004) Reform of Mental Healthcare. Praha: Ministry of Health. [In Czech] Czech Medical Society (2000) History of Czech Medical Society J. E. Purkyne. Praha: CLS JEP. [In Czech]

Kallert, T., Priebe, S., Kiejna, A., et al (2002) The European Day Hospital Evaluation (EDEN) study: an example of EC-funded mental health services research. In Psychiatry in Medicine and Medicine in Psychiatry (eds J. Raboch, P. Doubek \& I. Zrzavecká), pp. 103-108. Praha: Galen.

Kallert, T. W., Glöckner, M., Onchev, G., et al (2005) The EUNOMIA project on coercion in psychiatry: study design and preliminary data. World Psychiatry, 4, 168-172.

Health Statistics (2004) Psychiatric Care 2002. Praha: ÚZIS CR, Ministry of Health. [In Czech]

Raboch, J. (2003) The position of psychiatry among other medical disciplines. In Transformation of Psychiatry. Praha: Academia Medica Pragensis. [In Czech]

\title{
Teaching psychiatry in Ethiopia
}

\section{Charlotte Hanlon, ${ }^{1}$ Daniel Fekadu, ${ }^{2}$ Danny Sullivan, ${ }^{2}$ Atalay Alem ${ }^{3}$ and Martin Prince ${ }^{4}$}

'Wellcome Fellow in Tropical Clinical Epidemiology, c/o Department of Psychiatry, Faculty of Medicine, Addis Ababa University, PO Box 9086, Addis Ababa, Ethiopia, email charlhanlon@yahoo.com or c.hanlon@iop.kcl.ac.uk

${ }^{2}$ King's College London, Institute of Psychiatry, Department of Child and Adolescent Psychiatry, London, UK ${ }^{3}$ Department of Psychiatry, Faculty of Medicine, Addis Ababa University

${ }^{4}$ Professor and Head of the Section of Epidemiology, King's College London, Institute of Psychiatry, Department of Psychological Medicine, London, UK

Thereseng here is a pressing need to train psychiatrists in low- and middle-income countries. Psychiatrists from high-income countries have an opportunity to share expertise in teaching and assessing trainees, while learning much in the process. Three trainees from a London psychiatric hospital were invited to help organise a revision course for the Department of Psychiatry, Addis Ababa University, and this paper reports their experiences.

\section{Background}

Ethiopia, with a population of nearly 70 million (Central Statistical Authority, 2000), has less than one psychiatrist per 6 million people (Alem, 2004). The vast majority of people with a mental illness have no access to psychiatric treatments and instead rely on traditional methods (Alem, 2000). A major stumbling block to an increase in the numbers of psychiatrists in Ethiopia has been the need for doctors to obtain specialist psychiatric training abroad. This has inevitably led to a draining of psychiatrists away from Ethiopia to countries with greater rewards and career prospects. In additional, psychiatric training in high-income countries may not be wholly relevant to the Ethiopian setting.

In January 2003, the Department of Psychiatry at Addis Ababa University began postgraduate psychiatric training. The objective is to provide 'highly qualified clinical psychiatrists who would also teach other health professionals and conduct basic research in mental health in the country'. Since then, 23 trainees have received two half days of teaching per week and clinical supervision provided by psychiatrists from Amanuel Hospital and Addis Ababa University, together with intensive periods of teaching from visiting psychiatrists. Ultimately the teaching programme will be self-sufficient.

Through existing links between the Institute of Psychiatry, London, and the Department of Psychiatry, Addis Ababa University, psychiatrists from the Institute of Psychiatry were invited to assist with training Ethiopian psychiatrists. The teaching objectives were:

O to provide Ethiopian psychiatry trainees with experience of teaching and assessment methods commonly used in high-income countries

o to teach general examination skills relevant to the forthcoming end-of-year examination

o to introduce skills essential for continuing professional development.

\section{Methods}

The teachers

The visiting teachers, C.H., D.F. and D.S., were trained at a London psychiatric hospital and have extensive experience of teaching. The local teachers are Drs Abdulreshid Abdullahi (Associate Professor), Mesfin Araya (Assistant Professor and Head of Department) and Atalay Alem (Associate Professor). All are consultant psychiatrists who were trained overseas.

The teaching programme

This was developed in conjunction with the Department of Psychiatry, Addis Ababa University. Specific
A major stumbling block to an increase in the numbers of

psychiatrists in Ethiopia has been the need for doctors to obtain specialist psychiatric training abroad. This has

inevitably led

to a draining of psychiatrists away from Ethiopia to

countries with

greater rewards and career prospects. 

Ethiopian trainers, and included: multiple-choice questions (MCQs), essays, critical appraisal (in the form of a journal club), objective structured clinical examinations (OSCEs) and case presentations. We also asked the trainees to prepare a clinical presentation as a group in the form of a grand round. An important component was a mock examination that tested both written and clinical skills. Further details of the teaching programme are available from the authors.

Methods for
teaching and

assessment now

commonly used

in high-income

countries and

increasingly

favoured for

formal trainee

assessment

seemed to be

well received

by Ethiopian

psychiatry trainees.

The OSCEs were not used as a means of formal assessment but generated most reactions from the trainees.... 'It is a new and very difficult experience'.

\section{Outcomes}

The trainees' feedback is summarised in Table I.

\section{Formal assessment}

The majority of trainees found the MCQ examination the most difficult and performed least well in this part of the assessment, owing to difficulty interpreting the language of MCQs and unfamiliar topics. Performance in the essay examination was better, although the format was still unfamiliar to some. Essays were of good quality, with thoughtful, well constructed answers. Candidates seemed most comfortable in the clinical examination and rated this teaching module highly.

\section{Non-assessed modules}

The OSCEs were not used as a means of formal assessment but generated most reactions from the trainees. Initially this session was approached with some trepidation: 'It is a new and very difficult experience'. Later in the week trainees reported that this new mode of learning was beneficial: 'I was afraid ... to participate in role-playing but later on I found it [a] very good approach for me to [acquire] good skill'. Interestingly, the trainees gave the most positive feedback to the sessions in which they had had the greatest involvement: the grand round, journal club and OSCEs. They reported that critical appraisal skills areas of focus were needs led, as indicated by the

were daunting to acquire and that some of the papers critiqued in the journal club appeared less relevant to local needs.

\section{Discussion}

\section{Which training methods?}

Methods for teaching and assessment now commonly used in high-income countries and increasingly favoured for formal trainee assessment seemed to be well received by Ethiopian psychiatry trainees. Our teaching programme emphasised non-directive learning, in the form of OSCEs, a grand round and critical appraisal. These teaching modules scored most highly in the trainee feedback. The skills required for critical appraisal may seem technical, difficult to acquire without easy access to scientific journals and of a lower priority for hard-pressed clinicians; however, the benefits are likely to become increasingly apparent as access to free electronic journals becomes a reality.

\section{How to assess?}

The Ethiopian trainees performed well across assessments but struggled with the MCQs. In the UK, entrants to the psychiatry membership examination who had trained in a non-UK medical school were less likely to pass (Tyrer et al, 2002). The effect was, however, more marked with the clinical examination. The UK Royal College of Psychiatrists has expressed the hope that the introduction of OSCEs, with their more standardised assessment, will overcome the so-called 'linguistic bias' experienced by overseas students (Tyrer et al, 2002). By conducting our clinical assessment with local clinicians, any bias may have been circumvented.

\section{What to teach, and to whom}

Teaching priorities for Ethiopian psychiatrists will naturally differ from those of UK trainees, for example because of a different frequency of particular conditions, their presentation and the resources available for management. Different emphases within the curriculum are required to ensure Ethiopian trainees become psychiatrists well prepared for the challenges they will face in their own country.

A more contentious issue is whether valuable curriculum time should be spent learning about conditions, investigative techniques and therapies

Table 1 Trainees' feedback'

\begin{tabular}{lcccccccc}
\hline & $\begin{array}{l}\text { MCQ pre- } \\
\text { test }\end{array}$ & MCQs & OSCEs & $\begin{array}{l}\text { Journal } \\
\text { club }\end{array}$ & $\begin{array}{l}\text { Essay } \\
\text { skills }\end{array}$ & $\begin{array}{l}\text { Case } \\
\text { presentations }\end{array}$ & $\begin{array}{l}\text { Grand } \\
\text { round }\end{array}$ & $\begin{array}{l}\text { Teaching } \\
\text { objectives met }\end{array}$ \\
\hline Monday & $16 / 21$ & $17 / 21$ & $19 / 21$ & $18 / 21$ & & $16 / 18$ & & $17 / 18$ \\
Tuesday & & $16 / 21$ & $18 / 21$ & $19 / 21$ & $18 / 21$ & $18 / 21$ & & $16 / 21$ \\
Wednesday & & $19 / 21$ & $21 / 21$ & $21 / 21$ & & $20 / 21$ & $20 / 21$ & $20 / 21$ \\
Total & $16 / 21$ & $52 / 63$ & $58 / 63$ & $58 / 63$ & $18 / 21$ & $54 / 60$ & $20 / 21$ & $53 / 60$ \\
$(\%)$ & $(76 \%)$ & $(83 \%)$ & $(92 \%)$ & $(92 \%)$ & $(86 \%)$ & $(90 \%)$ & $(95 \%)$ & $(88 \%)$ \\
\hline
\end{tabular}

1. Grading of the components of the course by all trainees. Excellent $=3$, good $=2$, fair $=1$, poor $=0$. 
which have little immediate relevance in the Ethiopian setting. We argued that this was likely to facilitate greater inclusion in the worldwide community of psychiatrists, in terms of training recognition as well as ability to participate in research. A disadvantage raised by Jablensky (1999) is that Western conceptualisations of psychiatric illness and treatment may come to dominate, precluding the emergence of alternative understandings of mental ill-health.

Jacob (200I) has discussed the problems inherent in transferring models of psychiatric care provision from high-income to low-income countries. He raised questions about the appropriateness of focusing on psychiatrists as the longer-term providers of services to people who are mentally ill, although he sees a role for them more immediately in the training of non-specialist primary care personnel. Mental health nurses have been trained in Ethiopia since 1987 and provide most mental healthcare outside the capital city, albeit with psychiatric supervision. Future teaching collaborations may usefully provide consultancy for nursing education, as well as expertise from clinical psychologists.

\section{Where might training occur?}

As the number of Ethiopian psychiatrists working in Ethiopia has increased, together with government support, it has become possible to train psychiatrists in Ethiopia. Not having to send doctors abroad for their training may help to decrease the loss of psychiatrists to high-income countries. High-income countries have been accused of exploiting low-income countries to solve their own shortages of psychiatrists (Patel, 2003; and as discussed in previous issues of International Psychiatry). Psychiatrists trained within low- and middle-income countries are, however, still likely to be subject to models of psychiatric service and biomedical paradigms inherited from high-income regions. There is also concern that curricula in lowincome countries may be constrained to the acquisition of clinical skills, neglecting the role of the psychiatrist in research, service development and primary care (Farooq, 200 I).

For psychiatrists from high-income countries, experience of different systems, priorities and understandings of mental illness may enrich development, and usefully inform evolving psychiatric practice in the home country. Psychiatry trainees from high-income countries can learn skills useful to psychiatric practice in multicultural societies (Subramaniam, 2002).

\section{Developing a transferable collaborative teaching model}

We believe that psychiatrists from high-income countries have a role to play in assisting the training of mental health personnel in low-income countries. What can be most usefully offered will depend on the priorities of the country and existing educational resources. Transferable skills such as educational methods, modes of assessment and even the provision of well-worked curriculum materials could be areas where psychiatrists from the developed world can most usefully contribute. Where curricula are more established, expertise in psychiatric specialties may complement existing practice. Broadening the teachers and audience to include non-medical mental health workers recognises the crucial part they play in mental health provision.

We propose the following model for collaborative training:

training goals developed in close liaison with the host institution, addressing its priorities and needs

o trainee feedback to allow the training programme to be modified and more appropriately tailored as teaching proceeds

O sharing expertise in sub-specialisms of psychiatry, particularly substance misuse, forensic psychiatry, liaison psychiatry and child psychiatry

o visiting trainers having the opportunity to be able to learn about local services, common clinical presentations and conditions of work where they are teaching

O a commitment to regular and sustained input from outside trainers to allow better planning and integration within the existing curriculum.

\section{Structural support}

The Royal College of Psychiatrists has been called upon to develop partnerships with low- and middleincome countries; this should involve directly providing training appropriate to the needs of those countries and in return benefiting from the cultural exchange. The responsibility is to 'actively advocate equality of mental health worldwide' (Ghodse, 200I). The recent College initiative to support voluntary service overseas for specialist registrars could assist the provision of teaching expertise over an extended period. However, the College could play a more active part in promoting training activities, in the following ways:

O allowing overseas centres to register their interest with the College, stating their training needs and priorities

O suggesting standard clauses to be inserted into UK clinical contracts that would encourage the granting of study leave for these purposes

o lobbying the Department of Health for financial support, allowing the government to demonstrate its commitment to mutual development in the face of the International Fellowship Scheme.

\section{Conclusion}

One response to the critical shortage of mental health workers in the developing world is for high-income countries to make a commitment to mental health training worldwide. Our experience of teaching trainee psychiatrists in Ethiopia is that this can be a highly enjoyable and mutually enlightening process.
Transferable

skills such as

educational

methods, modes

of assessment

and even the

provision of well-

worked curriculum

materials could

be areas where

psychiatrists from

the developed

world can

most usefully

contribute.

The Royal College of Psychiatrists

has been called upon to develop partnerships with low- and middleincome countries;

this should involve directly providing training appropriate to the needs of those countries and in return benefiting from the cultural exchange. 


\section{Acknowledgements}

Drs Mesfin Araya, Abdulreshid Abdullahi and Menilik Desta are thanked for their kind hospitality. The Manchester course organisers, Dr Nigel Blackwood and Dr Al Santhouse, and Identic Ltd are thanked for allowing the use of the MCQs, and Dr Michael Dilley for the use of the OSCEs. We also thank Professor Robin Murray and Associate Professor I. Harry Minas, Director of the Centre for International Mental Health in Melbourne, Australia, for their departments' financial support.

\section{References}

Alem, A. (2000) Human rights and psychiatric care in Africa with particular reference to the Ethiopian situation. Acta Psychiatrica Scandinavica Supplementum, 399, 93-96.

Alem, A. (2004) Psychiatry in Ethiopia. International Psychiatry, issue $4,8-10$.
Central Statistical Authority (2000) Statistical Abstract of Ethiopia Addis Ababa: CSA.

Farooq, S. (200 I) Psychiatric training in developing countries. British Journal of Psychiatry, 179, 464.

Ghodse, H. (200I) Royal College of Psychiatrists' Board of International Affairs. Psychiatric Bulletin, 25, 363

Jablensky, A. (1999) Psychiatric epidemiology and the global public health agenda. International Journal of Mental Health, 28, $6-14$

Jacob, K. S. (200I) Community care for people with mental disorders in developing countries. Problems and possible solutions. British Journal of Psychiatry, I78, 296-298.

Patel, V. (2003) Recruiting doctors from poor communities: the great brain robbery? BMJ, 327, 926-928.

Subramaniam, H. (2002) Cross-cultural training in psychiatry. British Journal of Psychiatry, 180, 381.

Tyrer, S. P., Leung, W.-C., Smalls, J., et al (2002) The relationship between medical school of training, age, gender and success in the MRCPsych examinations. Psychiatric Bulletin, 26, 257-263.

\section{What is important for quality of life of psychiatrists?}

\section{Santosh K. Chaturvedi, MD MRCPsych}

Professor of Psychiatry, National Institute of Mental Health and Neurosciences, Bangalore, India, email chatur@nimhans.kar.nic.in

This paper was presented at the annual meeting of the Royal College of Psychiatrists, Edinburgh, 22 June 2005, at the session 'The recruitment and migration of psychiatrists from developing countries'. he concern for the mental health of people living in low-resource and industrially developing countries has been blown out of proportion. Economic well-being, as a psychological factor, has a complex association with mental health and may prove to be good or bad for it; after all, mental health in low- and middle-income countries (even with few psychiatrists!) is generally better than it is in high-income countries. Government funding may be low but there are innumerable sociocultural resources, many more than in most highincome countries. The number of psychiatrists per population may be low but numerous (informal and alternative) mental health services exist, many more popular and even more effective than psychiatry. The healthcare systems are so different that, whereas the average waiting period for a psychiatric patient in the UK may be about 90 days, it is about 90 minutes in India (and all patients are seen the same day). In fact, less than $10 \%$ of mental health problems are seen by psychiatrists!

It is sad to see that there is a publication bias, as only reports questioning the migration of health professionals are being published. The current tirade against migration smacks of prejudice against new National Health Service (NHS) fellows. Should psychiatrists from poor nations serve only patients in their home nation? Should they not venture (or earn) elsewhere, even if they are jobless and struggling in their own country? Is it right to leave high-income countries to their own mercy, even if they are short of staff? Is it ethical to let the jobless remain jobless, to let poor doctors remain poor, to destroy a professional's dreams and aspirations, to infringe on an individual's rights and freedom of choice, and to insist that a doctor born in a poor country remains there?

\section{The drift hypothesis}

The factors that persuade clinicians to emigrate are poor remuneration, bad working conditions, academic politics, job insecurity and the threat of violence, low standards of living, a wish to provide a good education for their children, and discrimination. Factors that force medical researchers to emigrate are lack of funding, poor facilities, limited career structures, poor intellectual stimulation and dissatisfaction. Health professionals are driven away from their home nations by lack of jobs (for example in India there are 250 training posts in psychiatry every year for less than 10 jobs), low wages, bureaucratic frustrations, indignity and stagnation. The saving grace has been provided by well paid jobs in the UK NHS and multiple opportunities offered by other high-income countries.

The NHS International Fellowship Programme has provided an avenue for those in permanent jobs to take a much-needed break from their routine, and thereby acts to postpone (or even prevent) eventual burnout. Consultant psychiatrists in India have no 